\title{
ALTERATIONS IN OPIOID INHIBITION CAUSE WIDESPREAD NOCICEPTION BUT DO NOT AFFECT ANXIETY-LIKE BEHAVIOR IN ORAL CANCER MICE
}

\author{
YI YE, ${ }^{a}$ DANIEL G. BERNABÉ, ${ }^{a \dagger}$ ELIZABETH SALVO, ${ }^{a}$ \\ CHI T. VIET, ${ }^{a, b}$ KENTARO ONO, ${ }^{a}$ JOHN C. DOLAN, ${ }^{a, b}$ \\ MALVIN JANAL, ${ }^{c}$ BRAD E. AOUIZERAT, ${ }^{a, b}$ \\ CHRISTINE MIASKOWSKI ${ }^{\mathrm{d}}$ AND BRIAN L. SCHMIDT ${ }^{\mathrm{a}, \mathrm{b} *}$ \\ a Bluestone Center for Clinical Research, College of Dentistry, \\ New York University, United States \\ ${ }^{\mathrm{b}}$ Department of Oral Maxillofacial Surgery, College of Dentistry, \\ New York University, United States \\ ${ }^{\mathrm{c}}$ Epidemiology and Health Promotion, College of Dentistry, New \\ York University, United States \\ ${ }^{\mathrm{d}}$ Department of Physiological Nursing, School of Nursing, \\ University of California at San Francisco, San Francisco, CA, \\ United States
}

\begin{abstract}
Widespread pain and anxiety are commonly reported in cancer patients. We hypothesize that cancer is accompanied by attenuation of endogenous opioidmediated inhibition, which subsequently causes widespread pain and anxiety. To test this hypothesis we used a mouse model of oral squamous cell carcinoma (SCC) in the tongue. We found that mice with tongue SCC exhibited widespread nociceptive behaviors in addition to behaviors associated with local nociception that we reported previously. Tongue SCC mice exhibited a pattern of reduced opioid receptor expression in the spinal cord; intrathecal administration of respective mu (MOR), delta (DOR), and kappa (KOR) opioid receptor agonists reduced widespread nociception in mice, except for the fail flick assay following administration of the MOR agonist. We infer from these findings that opioid receptors contribute to widespread nociception in oral cancer mice. Despite significant nociception, mice with tongue SCC did not differ from sham mice in anxiety-like behaviors as measured by the open field assay and elevated maze. No significant differences in c-Fos staining were found in anxiety-associated brain regions in cancer relative to control mice. No correlation was found between nociceptive and anxiety-like behaviors. Moreover, opioid receptor agonists did not yield a statistically significant effect on behaviors measured in the open field and elevated maze in cancer mice. Lastly, we used an acute cancer pain model (injection of cancer supernatant into the mouse tongue) to test whether adaptation to chronic pain is responsible for the absence of greater anxiety-like behavior
\end{abstract}

${ }^{*}$ Correspondence to: B.L. Schmidt, Bluestone Center for Clinical Research, New York University College of Dentistry, 421 First Avenue, 233W, New York, NY 10010, United States. Fax: +1-212995-484.

E-mail address: bls322@nyu.edu (B. L. Schmidt).

Current address: Oral Oncology Center and Department of Pathology and Clinical Propedeutics, Araçatuba Dental School, UNESP - Univ. Estadual Paulista, Araçatuba, São Paulo, Brazil. in cancer mice. No changes in anxiety-like behavior were observed in mice with acute cancer pain. (C) 2017 IBRO. Published by Elsevier Ltd. All rights reserved.

Key words: allodynia, cancer pain, anxiety, head and neck, widespread pain, nociception.

\section{INTRODUCTION}

Patients with oral squamous cell carcinoma (SCC) experience significant pain at the tumor site, which severely disrupts eating, drinking, and speaking (Hammerlid et al., 2001; Epstein et al., 2007; Viet and Schmidt, 2012). Prevalence of pain is estimated to be $75-90 \%$ among patients with advanced oral SCC (Epstein et al., 2007; van den Beuken-van Everdingen et al., 2007). Oral SCC pain is mediated, at least partially, by peripheral mechanisms (Schmidt et al., 2010). Central mechanisms, e.g., central sensitization, are not as well studied as the peripheral mechanisms. Central sensitization often yields pain in body regions distant from the site of injury (termed widespread pain) (Curatolo et al., 2006; Woolf, 2011). Widespread pain in non-cancer patients degrades quality of life and is a risk factor for poor response to pain treatment (Chen et al., 2012; Rabbitts et al., 2016). Sensory testing of healthy tissues distant from the cancer has never been performed in animal models. Accordingly, the presence or absence of widespread pain has not been documented in preclinical cancer models.

Central sensitization results from increased excitability and/or reduced inhibition in the central neural axis of the nociceptive pathway (Woolf, 2011). Endogenous opioids play an important inhibitory role in pain modulating mechanisms (Fields, 2004; Curatolo et al., 2006). Peripheral injury attenuates inhibitory mechanisms in the spinal cord by reducing the quantity of expressed opioid receptors; consequently the nociceptive signal transmitted to higher centers is amplified (Curatolo et al., 2006; Woolf, 2011). Opioid receptor agonists are the most common analgesics used to alleviate moderate to severe pain and are the mainstay of oral cancer pain treatment. Patients suffering from cancer pain generally require significantly higher doses of opioids than patients with inflammatory pain (Luger et al., 2002). Animal models demonstrate similar findings; the opioid dose required to block cancer pain-related behaviors in preclinical models 
is much higher than the dose required to block peak inflammatory pain behaviors (Luger et al., 2002). Cancer-induced reduction of endogenous opioid receptor activity and/or reduction in the quantity of receptors might explain the need for higher doses of exogenous opioids.

Central sensitization (induced by decreased opioid activity and/or receptor expression) might also contribute to psychological distress including anxiety. Many pain studies (not cancer related) in humans and in animals suggest that chronic pain and anxiety often cooccur (Zhang et al., 2014). The relationship between pain and anxiety seems to be reciprocal. Progressively greater pain leads to higher anxiety levels, while palliation of pain is associated with less anxiety (Sareen et al., 2005; Teh et al., 2009). Conversely, modulation of anxiety levels can alter pain levels (Heim and Oei, 1993; Chen et al., 2000; Delgado-Guay et al., 2009). Opioids attenuate both anxiety and pain in patients (Colasanti et al., 2011). A reduction in opioid tone may lead to widespread pain and anxiety.

In the current study we undertook the following: determine whether oral cancer generates widespread nociception; determine whether changes in widespread nociceptive behavior are caused by alterations in opioid receptor function or expression; and determine whether widespread nociception co-occurs with anxiety-like behaviors in a mouse model of oral cancer.

\section{EXPERIMENTAL PROCEDURES}

\section{Oral cancer cell culture}

HSC-3 (ATCC, Manassas, VA) derived from a human tongue SCC, was cultivated in supplemented Dulbecco's Modified Eagle's Medium (DMEM) at $37^{\circ} \mathrm{C}$ with $5 \% \mathrm{CO}_{2}$, as previously reported (Ye et al., 2011).

\section{Animal models of oral cancer}

Animals. We used female mice in the present study because women are more likely to experience both widespread pain and anxiety compared to men (Hammerlid et al., 1999; Linden et al., 2012). Moreover, despite well-recognized sex differences in pain and anxiety, studies on female animals are rare (Mogil, 2009; Belviranli et al., 2012; Simpson and Kelly, 2012). Six- to 8-week-old female BALB/c nude mice and BALB/c albino mice (Charles River Laboratories) were housed in a temperature controlled room on a 12:12 light/dark cycle (6 AM to 6 PM), with ad libitum access to food and water. All procedures involving animals were approved by the New York University Institutional Animal Care and Use Committee (IACUC) under protocol \# 160908-01, in accordance with the Guide for the Care and Use of Laboratory Animals published by the U.S. Institute for Laboratory Animal Research (8th edition). For all experiments, animals were habituated to handling prior to testing. A total of 10 sets of animals ( $n=222 \mathrm{BALB} / \mathrm{c}$ nude and $n=43 \mathrm{BALB} / \mathrm{c}$ albino) were used. No behavior data sets were combined for analysis to avoid experimental errors introduced by different experimenters.
Animal set 1: BALB/c nude mice with tongue cancer $(n=6)$ and sham mice $(n=6)$ were tested with facial von Frey in the morning followed by the dolognawmeter measurement at night at the baseline, and once per week after the day of HSC-3 inoculation (PID 0). At week 4 following the last dolognawmeter behavior measurement, all mice were euthanized, and spinal cords were dissected out for mRNA quantification of MOR, DOR, and KOR.

Animal set 2: BALB/c nude mice with tongue cancer ( $n=10)$ and sham mice $(n=10)$ were tested for paw and tail withdrawal at the baseline, and on a weekly basis after cancer inoculation. At week 4 following tail flick measurement, mice were sacrificed, perfused with PBS followed by $4 \%$ PFA. Brain tissues were prepared for c-Fos staining. Two brain tissue samples from each group were excluded for c-Fos analysis due to sectioning problems and excessive background staining.

Animal set 3: At week 4, BALB/c nude mice with tongue cancer $(n=20)$ and sham (21) were tested for OF and EZM assays on PID 21 and PID 24, respectively. These post-injection day times were chosen because pain behaviors were stabilized at week 4; there was no difference in all nociceptive behavior indices measured between week 3 and week 4 . In addition, since OF and EZM-induced anxieties are based on exposure to novel stimuli, to reduce the influence of one assay measurement on another assay measurement, a 3-day wash-out period was used. To determine the correlation of anxiety-like behaviors and nociceptive behaviors, the same set of cancer mice was then tested with paw withdrawal and tail flick assays on PID 27. The facial von Frey assay was conducted on PID 28 in the morning and the dolognawmeter at night. Two mice in the cancer group died before nociceptive behavior could be measured.

Animal set 4: Normal BALB/C albino mice were injected with either cancer supernatant $(n=16)$ or culture medium $(n=15)$ into the tongue and the animals were tested for anxiety-like behavior in the EZM assay one hour after anesthesia and supernatant injection. Due to the short-lasting effect of HSC-3 supernatant, and the two anxiety-like behavior assays cannot be tested within the same day, only the EZM assay was used

Animal set 5: On PID 21 the group of BALB/C nude mice with tongue cancer were treated intrathecally with the opioid receptor agonists for MOR, DOR, KOR and vehicle ( $n=8$ per group) and compared with mice without cancer $(n=8)$. Mice were evaluated with paw and tail withdrawal assays one hour after opioid receptor agonist treatment.

Animal set 6: On PID 21 tongue cancer mice were treated intrathecally with the opioid receptor agonists for MOR, DOR, KOR and vehicle ( $n=8$ per group) and tested in the OF one hour after drug injection. Normal mice without cancer $(n=8)$ were administered intrathecal injection of PBS.

Animal set 7: On PID 24 another group of tongue cancer mice were treated intrathecally with the opioid receptor agonists for MOR, DOR, KOR and vehicle 
( $n=8$ per group) and were tested in the EZM one hour after drug injection. Normal mice without cancer $(n=8)$ were administered intrathecal injection of PBS.

Animal set 8: To quantify protein levels of MOR, DOR, KOR, 5 tongue cancer and 4 sham mice were euthanized at week 4 . Spinal cords at the L4-5 region were surgically removed and snap frozen in liquid nitrogen for protein extraction.

Animal set 9: HSC-3 supernatant or DMEM was injected into the tongue of BALB/C albino mice, supernatant injected $(n=6)$ or DMEM injected $(n=6)$ mice were tested in the dolognawmeter.

Animal set 10: MOR, DOR, KOR agonist or vehicle was injected intrathecally in naïve BALB/c nude mice. Paw withdrawal and tail flick assays were performed following drug treatment ( $n=5$ per group).

Chronic cancer pain model. We produced a chronic cancer pain model by injecting HSC-3 cells into the tongues of $\mathrm{BALB} / \mathrm{c}$ nude mice as previously reported (Ye et al., 2011). Fifty $\mu$ of $10^{6}$ HSC-3 cells in a DMEM and Matrigel ${ }^{\mathrm{TM}}$ mixture (Becton Dickinson \& Co., Franklin Lakes, NJ) was injected into the right side of tongue under isoflurane anesthesia. The sham control group received $50 \mu$ of vehicle alone (DMEM and Matrigel ${ }^{\mathrm{TM}}$ mixture) in the tongue.

Acute cancer pain model. The acute cancer pain model (injection of cancer supernatant into the mouse tongue) allowed us to test whether cancer mediators alone can produce anxiety, and whether acute cancer pain differs from chronic cancer pain in producing anxiety behavior. HSC-3 cell cultures were grown to confluence and then further incubated in serum free DMEM for $48 \mathrm{~h}$ prior to supernatant collection as we previously described (Ye et al., 2012). Fifty $\mu$ of the supernatant was injected into the tongue of mice under isoflurane anesthesia. The sham control group received $50 \mu \mathrm{l}$ of media incubated without cancer cells.

\section{Nociceptive behavior measurements}

Paw withdrawal assay. Paw withdrawal thresholds were measured using an electronic von Frey anesthesiometer (IITC Life Science, Woodland Hills, CA). Animals were placed separately into acrylic boxes with wire-mesh floor and were allowed to acclimate for $30 \mathrm{~min}$. The mechanical stimulation was applied to the mouse right hind paw. Withdrawal threshold was defined as the minimally sufficient force (gram-force) required to elicit withdrawal response. The mean of six measurements taken for each animal was used as the respective threshold.

Tail pinch assay. Each mouse was placed into an individual mouse restrainer with the tail positioned outside the enclosure; mice were allowed to acclimate for 10-15 min. A tail pincher (\#2455, IITC Life Science, Woodland Hills, CA) was applied to the tail $1 \mathrm{~cm}$ from the tip. Data were recorded once a clear tail flick was observed. The mean of 5 measurements was used as the threshold for each animal.

Facial von Frey. Each animal was placed into customized restrainers; the head of the mice remained outside the restrainer. Mice were allowed to acclimate for 10-15 min (Romero-Reyes and Ye, 2013; Ono et al., 2015). Mechanical sensitivity was determined with a graded series of eight von Frey filaments (0.07-4.00 grams, Stoelting, Wood Dale, IL, USA) applied to the mice right vibrissa. The force generated by the most flexible filament that produced a brisk head withdrawal upon mechanical stimulation was considered to be the response threshold (Romero-Reyes and Ye, 2013; Ono et al., 2015). Withdrawal threshold was expressed in gram-force.

Gnawing assay. The dolognawmeter assay is a validated instrument for quantifying oral function and orofacial nociception in mice (Dolan et al., 2010; Ye et al., 2011). In the dolognawmeter, each mouse was placed into a confinement tube with 2 obstructing dowels in series. Each obstructing dowel is connected to a retraction spring and digital timer. When the gnawing of the mouse severs the dowel, the timer automatically records the duration of time required to accomplish the gnawing task. To acclimatize the mice and improve consistency in gnawing duration, all mice were trained for at least 10 sessions to establish a stable baseline gnaw-time value. Baseline gnaw-time was established as the mean gnawtime over three sessions for each mouse. Mice were subsequently inoculated with cancer cells. A cut-off time of $12 \mathrm{~h}$ was used. We infer greater orofacial nociception in mice that exhibit gnaw-times greater than baselines values.

\section{Anxiety-like behavior}

Open field (OF). The open field test of locomotion and anxiety (Stoelting Co., Wood Dale, IL) was performed under dim light (30 lux). Mice were allowed to freely explore for $30 \mathrm{~min}$ inside the apparatus chamber measuring $40 \times 40 \mathrm{~cm}$, containing an outer zone $(10 \mathrm{~cm}$ from the walls) and a square open center zone $(20 \mathrm{~cm} \times 20 \mathrm{~cm})$. Activity was video recorded and analyzed using the ANY-maze software (Stoelting Co., Wood Dale, IL). Distance traveled was used as the measure of locomotor activity; time spent in the center zone was used as the measure of anxiety; we infer that there is less anxiety in animals that spend greater time in the center zone (Urban et al., 2011).

Elevated zero maze (EZM). Mice were tested with the EZM apparatus (Stoelting Co., Wood Dale, IL) under dim light (15 lux). Mice were placed within the enclosed area of the maze. Activity was recorded for $10 \mathrm{~min}$ by a video camera mounted above the maze. Time spent in the open arm was later scored and used to quantify anxiety level (Urban et al., 2011). 
Measurement of defecation. Quantification of fecal boluses has been proposed as a method to characterize levels of anxiety (Kalueff and Tuohimaa, 2004). After behavior was measured in the OF and EZM assays, the quantity of individual fecal boluses found in the assay devices was recorded for each mouse as an additional indicator of anxiety-like behaviors.

C-Fos staining. C-Fos is a commonly used marker of neuronal activity. Mice brains were removed, fixed in $4 \%$ PFA and cryoprotected in $25 \%$ sucrose. Frozen brains were cut into $20-\mu \mathrm{m}$-thick coronal sections using a Leica cryostat $\mathrm{CM} 3050$ and incubated in $0.3 \% \mathrm{H}_{2} \mathrm{O}_{2}$. Sections were blocked and incubated with c-Fos primary antibody (Calbiochem, 1:4000) overnight at $4{ }^{\circ} \mathrm{C}$ followed by 2-h incubation at room temperature in biotinylated goat antirabbit secondary antibody (Vector Laboratories, 1:500). The primary-secondary complex was mixed with avidinbiotinylated enzyme complex/3,3'-diaminobenzidine techniques (Elite ABC/DAB Kit; Vector Laboratories, Burlingame, CA). C-Fos immunoreactivity was counted by two observers blinded to the group assignment using NIH Image J software. The brain regions were identified anatomically in accordance with a stereotaxic mouse brain atlas (Paxinos and Franklin, 2008). Expression of c-Fos was assessed in the following anxiety-related brain regions: bed nucleus of stria terminalis (BNST, bregma $+0.38 \mathrm{~mm}$ to $+0.14 \mathrm{~mm}$ ); medial amygdala (MeA) and central amygdala $(\mathrm{CeA})$ (bregma, $-1.58 \mathrm{~mm}$ ), and paraventricular nucleus of the hypothalamus (PVN, bregma $-0.82 \mathrm{~mm})$.

\section{Drug administration}

Drugs employed in this study include [D-Ala2, N-MePhe4, Gly-ol]-enkephalin (DAMGO, 0.05mg/kg) and (+)-4$[(\alpha R)-\alpha-((2 S, 5 R)-4-$ Allyl-2,5-dimethyl-1-piperazinyl)-3-met hoxybenzyl]-N,N-diethylbenzamide (SNC80, $500 \mathrm{ng} / \mathrm{kg}$ ) from Tocris Bioscience (Ellisville, MI), and Salvinorin A $(0.2 \mathrm{mg} / \mathrm{kg}$, Sigma, St. Louis, MO). SNC80, DAMGO, and Salvinorin A are highly selective agonists for DOR, MOR and KOR, respectively. Drug or vehicle $(5 \mu \mathrm{L}, 5 \%$ DMSO in PBS) was administered intrathecally. Mice were first anesthetized with $4 \%$ isoflurane, followed by $2 \%$ isoflurane administration through a nose cone during the injection. A $10-\mu$ l Hamilton syringe with a $30 \varnothing \mathrm{G}$ needle was inserted in between the groove of L5 and L6 vertebrae. The successful entry of the needle was confirmed with a tail flick. The experimenter has previously practiced this technique with fast blue injection, to ensure the proper delivery of the solution through intrathecal injection. Animals were allowed to recover from anesthesia for one hour before proceeding to either paw withdrawal, tail withdrawal, OF, or EZM testing. Drug treatment and behavioral testing were conducted at week 4 following HSC-3 inoculation.

\section{Real-time PCR}

A lumbar segment of the spinal cord ( $n=6$ from cancer and $n=6$ from control) around L4-5 region was surgically removed from each mouse and stored at $-80^{\circ} \mathrm{C}$ until further processing. Total RNA of each sample was isolated with Qiagen DNA/RNA kit (Qiagen Inc., Valencia, CA). Reverse transcription (RT) was carried out using High Capacity cDNA Reverse Transcription Kit (Applied Biosystems Inc., Foster City, CA) on the Biometra thermocyler. All qPCR assays were performed with Taqman gene expression assay kit (Applied Biosystems Inc.). Cycling conditions consisted of 1 cycle of $50^{\circ} \mathrm{C}$ for 2 min followed by $95^{\circ} \mathrm{C}$ for $10 \mathrm{~min}$, and then 40 cycles of $95^{\circ} \mathrm{C}$ for $15 \mathrm{~s}$ followed by $60^{\circ} \mathrm{C}$ for $1 \mathrm{~min}$. The housekeeping gene $\beta$-actin (ACTB) was chosen as the internal control. Relative quantification analysis of gene expression data was conducted according to the $2-\Delta \Delta \mathrm{CT}$ method.

\section{Protein quantification}

For MOR, DOR, KOR protein quantification, a lumbar segment of the spinal cord around L4-5 region and brainstem ( $n=5$ from cancer and $n=4$ from sham control) were surgically removed. The isolated tissue samples were mechanically homogenized in ice-cold RIPA buffer (Thermofisher Scientific, Waltham, MA) with $10 \%$ protease inhibitor cocktail (Thermofisher Scientific, Waltham, MA). Homogenates were centrifuged at $13,000 \mathrm{~g}$ for $10 \mathrm{~min}$ at $4^{\circ} \mathrm{C}$. The supernatant was collected and stored at $-80^{\circ} \mathrm{C}$. Protein concentrations of the homogenate were determined using BCA protein assay kit (Thermofisher Scientific, Waltham, MA). For the Western Blot analysis $20 \mu \mathrm{g}$ of protein extract was fractionated on a $12 \%$ Mini-Protean TGX gel (Bio-Rad) and transferred onto nitrocellulose membrane (Thermo Fisher Scientific). Membranes were blocked for $1 \mathrm{~h}$ with $5 \%$ non-fat milk in PBS containing $0.1 \%$ Tween-20, and then incubated overnight at $4{ }^{\circ} \mathrm{C}$ at a $1: 1000$ dilution with either anti-DOR (Abcam, ab176324), anti-KOR (Santa Cruz Biotechnology, sc-9112), Anti-MOR (Abcam, ab10275) or anti-GAPDH antibody (Cell Signaling, 2118). HRP-conjugated goat anti-rabbit IgG (Santa Cruz Biotechnology, sc-2030) was used as the secondary antibody at a 1:5000 dilution. The signal was detected by Clarity Western ECL Substrate (Bio-Rad) and analyzed using ChemiDoc MP Imaging System with Image Lab Software (Bio-Rad).

\section{Statistical analysis}

GraphPad Prism 5 was used to perform the statistical analysis. Data were checked for normal distributions using D'Agostino \& Pearson omnibus normality test. Student's t-test or Mann-Whitney U-test assuming unequal variances was used to compare two groups depending on data normality. Two-way Analysis of Variance (ANOVA) was used to examine the interaction between time and treatment, followed by post hoc Sidak's multiple comparison for the main treatment effect. One-way ANOVA with a Tukey's multiple comparisons post hoc test was used to compare multiple groups, and simple linear regression analysis was used to determine the correlation between nociceptive behaviors (as measured by paw and facial withdrawal thresholds, gnaw-time) and anxiety-like 

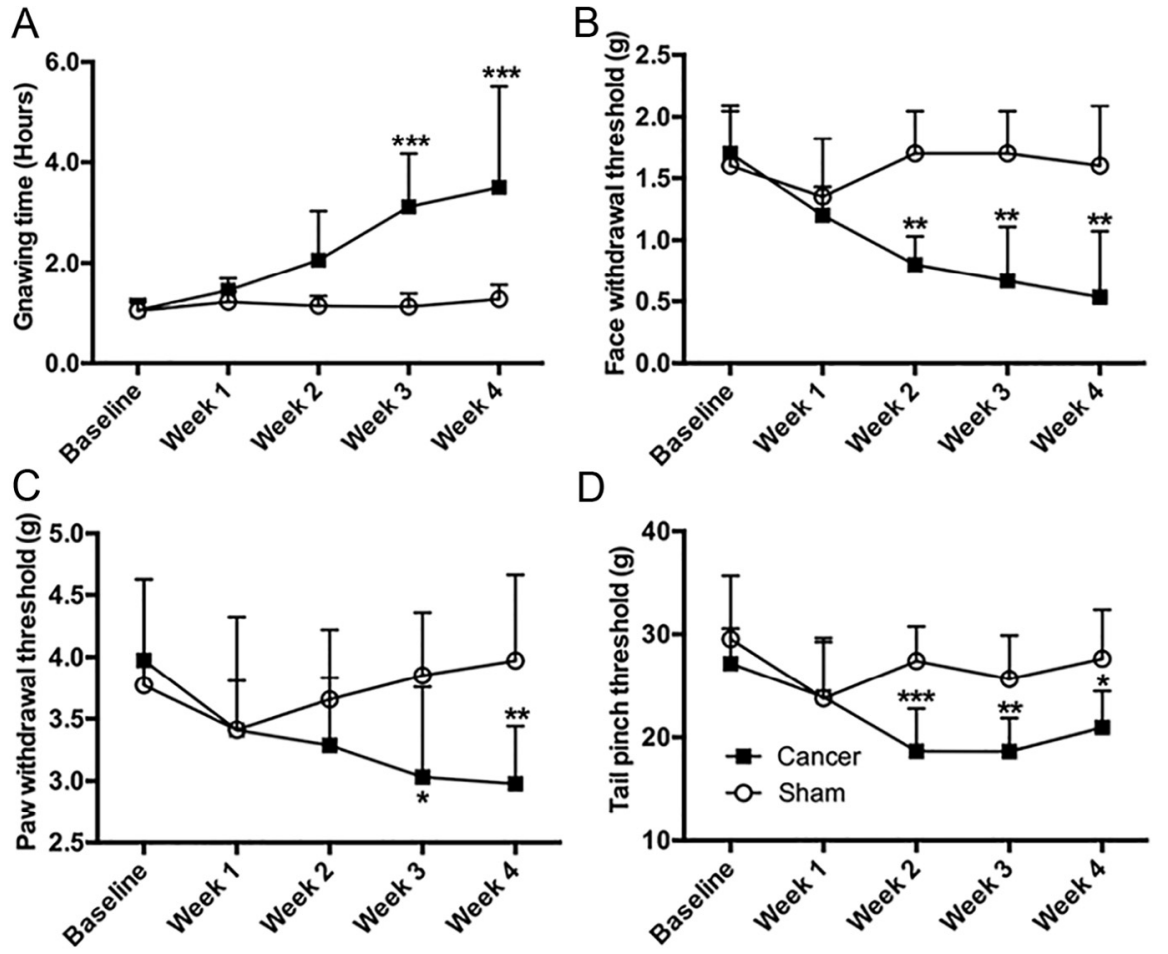

Fig. 1. SCC mice exhibited local and widespread nociception. (A) Mice with tongue cancer $(n=6)$ required significantly more time to complete the gnawing task in the dolognawmeter compared to the sham mice $(n=6)$ measured at PID weeks 3, and 4. Interaction: $F(4,50)=4.689, p<0.01$; time factor: $F(4,50)=5.640, p<0.001$; group factor: $F(1,50)=26.86, p<10^{-4}$. Post-hoc analysis for the time effect only detected significant difference in gnaw time at weeks $2,3,4$ compared to baseline and week 1 in tongue cancer mice; no difference in gnaw time was detected among the week 2, week 3 and week 4 in the tongue cancer group. (B) Mice with tongue cancer $(n=6)$ exhibited a lower mechanical threshold in the face compared to the sham mice $(n=6)$ measured at weeks 2,3 , and 4 following cancer inoculation. Interaction: $F(4,50)=3.586$, $p<0.05$; time factor: $F(4,50)=2.325, p=0.08$; group factor: $F(1,50)=22.48, p<0.001$ (C) Mice with tongue cancer $(n=10)$ exhibited a lower paw withdrawal threshold at week 3 and week 4 compared to sham mice $(n=10)$. Interaction: $F(4,50)=3.586, p<0.05$; time factor: $F(4,90)$ $=1.668, p=0.17$; group factor: $F(1,90)=8.522, p<0.01$ (D) Mice with tongue cancer $(n=10)$ exhibited a significantly lower tail pinch threshold at weeks 2,3 , and 4 compared to sham mice $(n=10)$. Interaction: $F(4,90)=3.152, p<0.05$; time factor: $F(4,90)=5.344, p<0.001$; group factor: $F(1,90)=27.81, p<10^{-4}$. Post-hoc analyses for the time effect detected a significant difference in gnaw time at weeks 2,3 , and 4 compared to baseline in tongue cancer mice. No difference in gnaw time was detected among weeks 2, 3 and 4 in the tongue cancer group. ${ }^{*} p<0.05,{ }^{* *} p<0.01,{ }^{* \star *} p<0.001$, cancer and sham control, two-way ANOVA followed by post hoc Sidak's multiple comparisons for the group effect.

behaviors (as measured in the OF and EZM). The threshold for statistically significant differences was $p<0.05$. Results were presented as mean \pm standard error of the mean (SEM).

\section{RESULTS}

\section{Oral cancer caused both local and widespread nociceptive behavior}

To preclude physical exhaustion from multiple measurement regimens at the same time point, we used two sets of mice to measure nociceptive behaviors. The first set of BALB/C nude mice with tongue cancer $(n=6)$ and sham mice $(n=6)$ were trained in the dolognawmeter and tested with facial von Frey filaments before HSC-3 inoculation (post-inoculation day, PID 0). Mice were tested in the dolognawmeter and with facial $p<10^{-4}$ ). von Frey filaments on a weekly basis for 4 weeks. The second set of mice included 10 animals with tongue cancer and 10 sham mice. Paw and tail withdrawal were assessed following the same testing regimen employed on the first set of animals.

Consistent with our previous findings (Ye et al., 2011), mice with tongue cancer exhibited greater gnaw-time compared to sham mice (Fig. 1A). The gnaw-time in tongue cancer mice was significantly increased at week $3(t(10)=4.29$, $p<0.001)$ and week 4 (t(10) $=4.80, \quad p<0.001)$ compared to sham mice. We infer cancer-induced mechanical allodynia from this finding. The mechanical threshold of von Frey filament stimulation in the facial region was lower at week $2(t(10)$ $=3.13, p<0.01)$, week $3(t(10)$ $=3.59, p<0.01)$, and persisted into week $4(t(10)=3.71, p<0.01)$ in mice with tongue cancer compared to sham mice (Fig. 1B). Mice with tongue cancer exhibited lower mechanical von Frey thresholds in the right hind paw compared to sham mice at week 3 (Fig. 1C, $t(18)=2.64$, $p<0.05$ ) and week 4 (Fig. 1C, t(18) $=3.20, \quad p<0.01)$. Mechanical thresholds in the tail of mice with tongue cancer were lower compared to sham mice at week $2(t(18)=4.18$, $p<0.001)$, week $3(t(18)=3.26$, $p<0.01$ ), and week 4 (Fig. 1D, $t$ $(18)=3.08, p<0.05)$.

\section{Oral cancer mice did not exhibit increased anxiety-like behavior}

Both sham mice $(n=21)$ and cancer mice $(n=20)$ exhibited large variation in anxiety-like behaviors in the OF assay at week 4 (Fig. 2A-B). Distance traveled (Fig. $2 \mathrm{C}, t(39)=1.577, p=0.12$ ) and time spent in the inner zone (Fig. 2D, $t(39)=0.37, p=0.72$ ) were not statistically different between cancer and sham mice in the OF assay There was no difference in time spent in the open arms in the EZM assay between cancer and control mice at week 4 (Fig. $2 \mathrm{E}, t(39)=1.35, p=0.19$ ). These observations accord with defecation measurements. The number of fecal boluses did not differ statistically between sham and cancer mice in the OF (Fig. $3 A, t(39)=0.46, p=0.65$ ) or the EZM assay (Fig. $3 \mathrm{~B}, t(39)=1.12, p=0.27$ ). Mice with tongue cancer lost weight while sham mice gained weight relative to their baseline (Fig. $3 C, t(39)=11.56$,

We collected mouse brains for c-Fos staining. Consistent with behavioral data, c-Fos expression did 

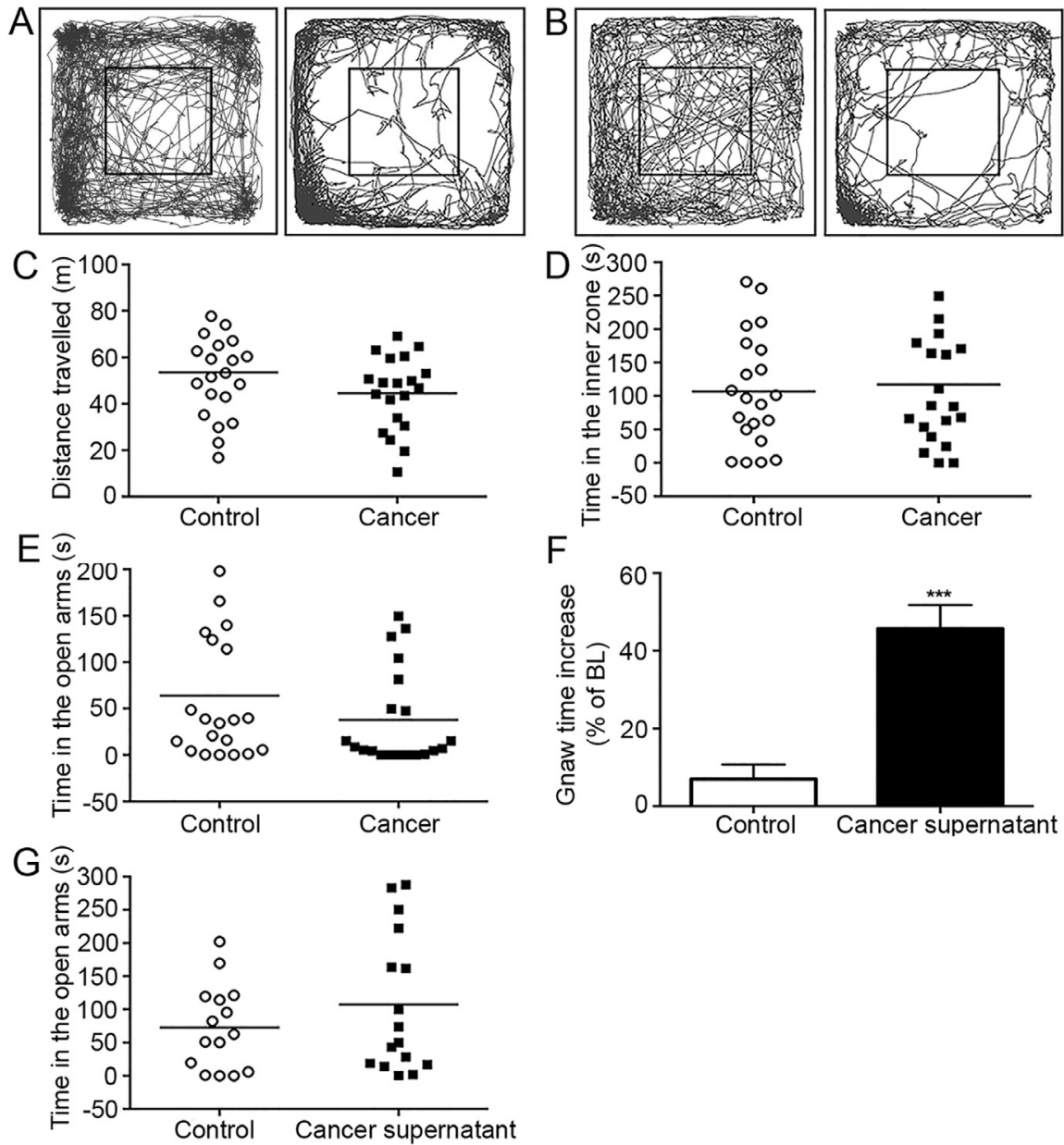

Fig. 2. SCC mice and sham mice showed no difference in behaviors measured by OF and EZM. (A) Tracing example of a mouse with tongue cancer that stayed in the inner zone for an extended duration while another mouse with tongue cancer remained in the inner zone of the OF for a short period of time. (B) Tracing example of a sham mouse that spent an extended period of time in the inner zone while another sham mouse spent little time in the inner zone of the OF. (C) The distance traveled by cancer mice $(n=20)$ and sham mice $(n=21)$ in the OF assay was not significantly different. (D) Time spent in the inner zone of the OF was not different between the cancer and sham mice. (E) No significant difference was observed in mice with tongue cancer compared to sham mice in the EZM. (F) Gnaw-time was significantly increased in mice injected with cancer supernatant into the tongue $(n=6)$ compared to vehicle-injected mice $(n=6)(G)$ No difference in time spent in open arms was observed between cancer supernatant $(n=16)$ and vehicle-injected mice $(n=15)$. Student's t-test and Mann-Whitney U-test. ${ }^{\star \star *} p<0.001$

not differ significantly between cancer $(n=8)$ and sham mice $(n=8)$ in the four anxiety-related brain areas we analyzed: BNST, cancer $(21.16 \pm 7.0$ cells $)$ and sham $(15.06 \pm 2.3$ cells) (Fig. $4 \mathrm{~A}, t(8.56)=0.82, p=0.43)$; MeA, cancer $(24.85 \pm 7.1$ cells $)$ and sham $(19.25 \pm 4.5$ cells) (Fig. 4B, $t(14)=0.66, p=0.52)$; CeA, cancer $(12.12 \pm 5.8$ cells $)$ and sham $(11.08 \pm 3.8$ cells $)$ (Fig. $4 \mathrm{C}, t(14)=0.15, p=0.88)$; PVN, cancer $(29.08$ \pm 10.7 cells) and sham $(20.66 \pm 6.1$ cells) (Fig. 4D, $t$ (14) $=0.68, p=0.51$ ).

To determine whether the lack of change in anxietylike behaviors in cancer mice is due to adaptation to ongoing nociception and cancer growth, we tested anxiety-like behaviors in an acute (i.e., cancer supernatant injection) cancer pain model. Cancer supernatant is known to cause acute nociception that lasts for several hours (Ye et al., 2012). We reconfirmed in a separate set of BALB/c mice that HSC-3 supernatant injection into the tongue induced acute nociception (Fig. $2 \mathrm{~F}$, $U=0, \quad p<0.01)$. Thirty minutes after cancer supernatant injection into the tongue, mice were tested in the EZM. Similar to findings in the chronic tongue cancer model, we did not observe a statistically significant difference between cancer supernatant $(n=16)$ and DMEM-injected control mice $(n=15)$ with regard to time spent in the open arms of the EZM (Fig. 2G, $t(29)=1.09$, $p=0.29$ ).

\section{Nociception levels were not correlated with anxiety-like behavior}

We observed wide variation in anxiety-like behavior and nociceptive behavior in cancer mice. Using linear regression analyses we sought to determine whether high levels of nociception predict higher anxiety levels in cancer mice. After the OF and EZM assays at week 4, mice were tested with the facial von Frey assay, paw withdrawal assay, and dolognawmeter. No correlation between nociceptive behavior and anxiety-like behavior was observed in any of the assays: paw withdrawal threshold and time in the inner zone of the OF (Fig. 5A, $r^{2}=0.00$, $p=0.84$ ); paw threshold and time in open arms in EZM (Fig. 5B, $\left.r^{2}=0.06, p=0.32\right)$; face threshold and time in the inner zone of the OF (Fig. 5C, $r^{2}=0.12, p=0.15$ ); face threshold and time in open arms in EZM (Fig. 5D, $r^{2}=0.09, p=0.22$ ); gnaw-time in the dolognawmeter and time in the inner zone of the OF (Fig. 5E, $r^{2}=0.18, p=0.08$ ); and gnaw-time in the dolognawmeter and time in open arms in EZM (Fig. 5F, $\left.r^{2}=0.05, p=0.38\right)$

\section{Spinal opioid receptor subtypes modulate cancer- induced global nociception but not anxiety-like behavior}

To determine whether oral cancer affects expression levels of opioid receptors in the spinal cord, the lumbar segments of the spinal cord were collected at week 4 for mRNA and protein quantification. The DOR mRNA was significantly down regulated in the spinal cord of mice with tongue cancer $(n=6)$ compared to sham mice $(n=6$; Fig. $6 \mathrm{~A}, U=1, p<0.01)$. No statistically 
A

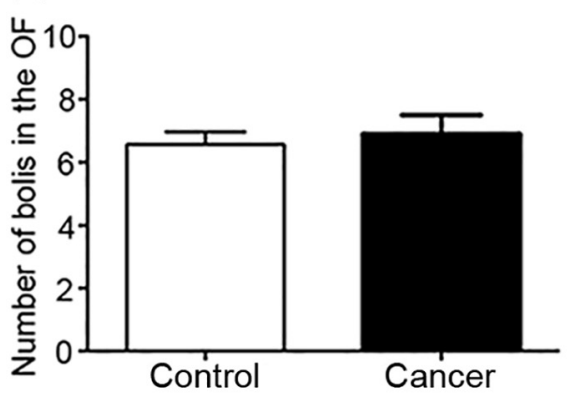

B

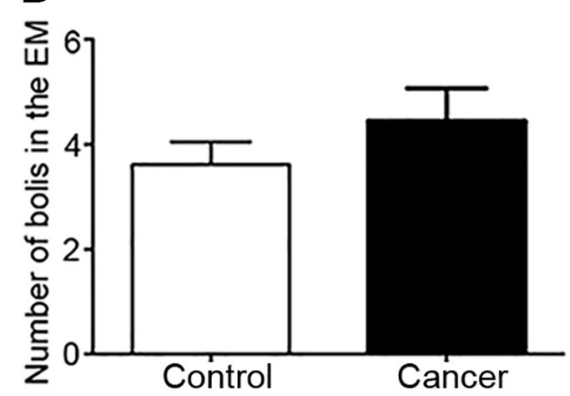

C

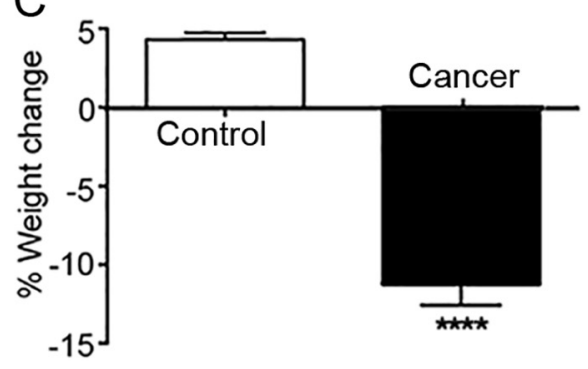

Fig. 3. Oral cancer and sham mice did not differ in defecation despite significant weight loss. (A) The number of fecal boluses was not significantly different between sham $(n=21)$ and cancer mice $(n=20)$ in the OF assay. (B) The number of fecal boluses was not significantly different between sham and cancer mice in the EZM. (C) Mice with tongue cancer lost weight while sham mice gained weight relative to their baseline. Student's t-test. ${ }^{* \star *} p<10^{-4}$.

A
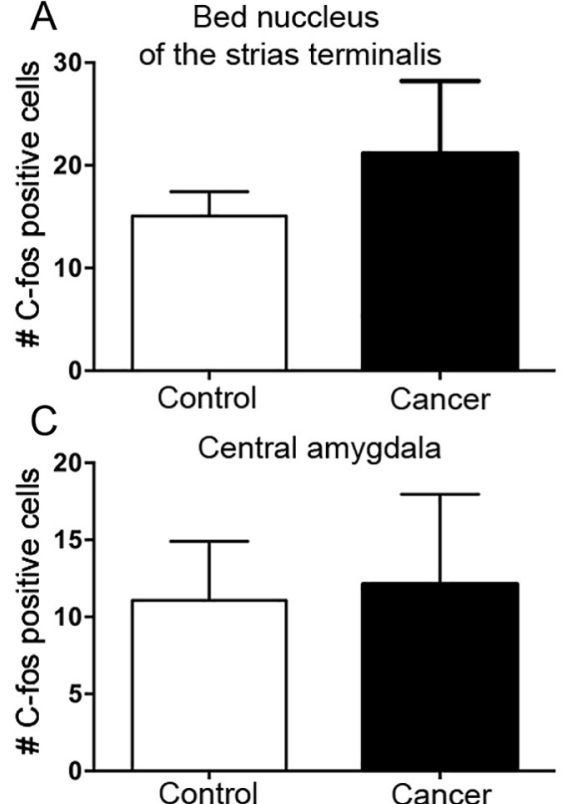

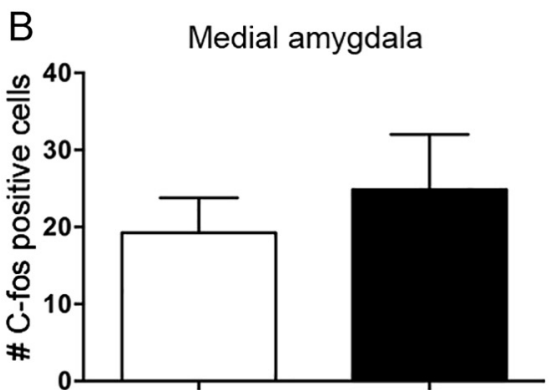

Control

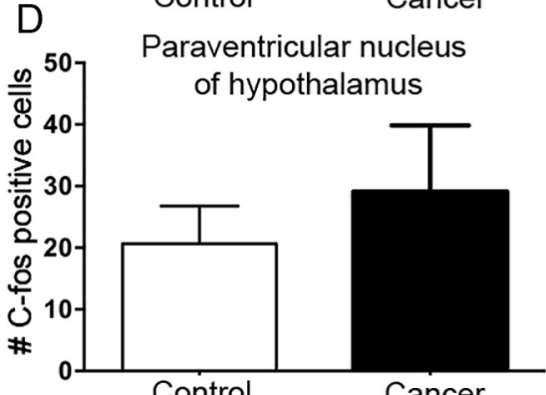

Fig. 4. Oral cancer and sham mice did not differ in c-Fos immunopositivity in anxiety-associated brain areas. (A-D) c-Fos immunopositivity was not different in the BNST, MeA, CeA, and PVN between mice with tongue cancer $(n=8)$ and sham mice $(n=8)$. Student's t-test.

significant differences were found in MOR (Fig. 6A, $U=12, p=0.37$ ) or KOR mRNA (Fig. $6 \mathrm{~A}, U=12$, $p=0.23$ ) expression levels in the spinal cord between mice with tongue cancer and sham mice. Both DOR (Fig. 6B, $U=0, p<0.05$ ) and MOR protein expression
(Fig. 6B, $\quad U=0, \quad p<0.05$ ) were significantly reduced in the spinal cord of mice with tongue cancer $(n=5)$ compared to sham mice $(n=4)$. No difference was found for KOR protein expression in the spinal cord between mice with tongue cancer and sham mice (Fig. 6B, $U=8, p=0.67$ ).

Protein quantification of opioid receptors in the brainstems revealed that both MOR (Fig. $6 \mathrm{C}$, $U=1, \quad p<0.05) \quad$ and $\mathrm{KOR}$ protein expression (Fig. $6 \mathrm{C}, U=1$, $p<0.05)$ were significantly reduced in mice with tongue cancer $(n=5)$ compared to sham mice $(n=4)$. No difference was found for DOR protein expression in the brainstem between mice with tongue cancer and sham mice (Fig. $6 \mathrm{C}, U=7, p=0.88$ ).

Because functional changes in opioid receptors could also exist in cancer mice, we injected selective opioid receptor agonists intrathecally to determine the differential effect of MOR, DOR, and KOR on generalized nociception and anxietylike behaviors ( $n=8$ per group). We found that the DOR agonist SNC80 significantly attenuated cancerinduced mechanical hypersensitivity in the tail (Fig. 7A, $q(4,35)=6.62$, $p<10^{-4}$ ) and the paw (Fig. 7B, $q$ $\left.(4,35)=p<10^{-4}\right)$. Similarly, KOR agonist Salvinorin $A$ also reduced cancer-induced mechanical hypersensitivity in the tail (Fig. 7A, $q$ $\left.(4,35)=10.41, p<10^{-4}\right)$ and the paw (Fig. 7B, $q(4,35)=4.04$, $p<0.001)$. MOR agonist DAMGO significantly reversed mechanical allodynia in the paw (Fig. 7B, $q$ $(4,35)=2.91, \quad p<0.05)$, while it had no effect on tail withdrawal thresholds (Fig. 7A, q $(4,35)=1.29$, $p=0.29)$. The same treatment regimen of DOR, KOR, and MOR agonists had no significant effect on anxiety-like behavior in either sham mice or vehicle-treated cancer mice, as measured by distance traveled (Fig. $7 C, F(4,35)=0.46, p=0.76)$, or time spent in the inner zone of the OF (Fig. 7D, $\quad F(4,35)=1.15$, $p=0.35)$, and EZM assays (Fig. 7E, $F(4,35)=0.46, \quad p=0.76$ ) at week 4 . None of these agonists had an effect on tail flick and paw withdrawal thresholds in naïve mice when injected intrathecally (Fig. 7F, $n=5$ per group, two-way ANOVA, $p>0.05)$. 
A
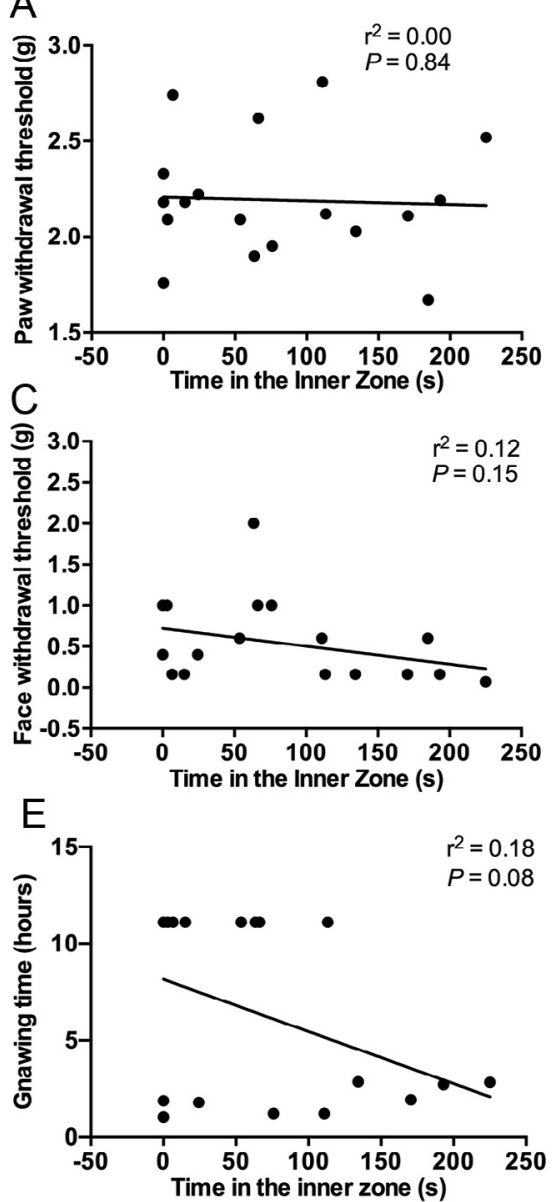

B

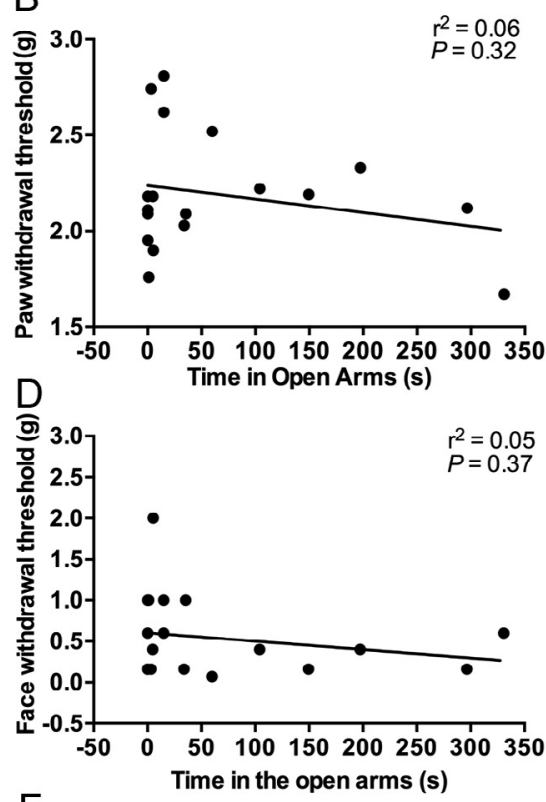

$\mathrm{F}$

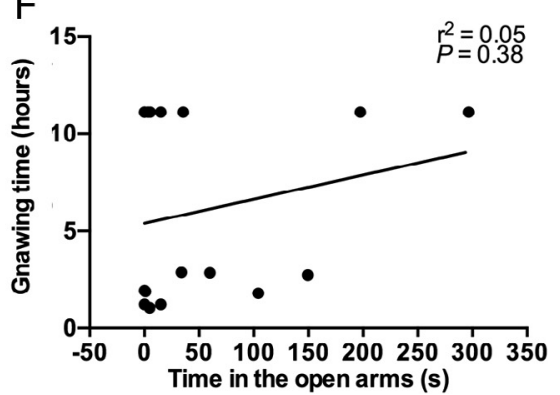

Fig. 5. Nociceptive behaviors did not correlate with behaviors measured in the OF or EZM. (A) Paw withdrawal thresholds are not correlated with time spent in the inner zone of the OF in mice with tongue cancer $(n=18)$. (B) Paw withdrawal thresholds are not correlated with time spent in open arms of the EZM in mice with tongue cancer $(n=18)$. (C) Face withdrawal thresholds are not correlated with time in the inner zone of the OF in mice with tongue cancer ( $n=18)$. (D) Face withdrawal thresholds are not correlated with time spent in the open arms of the EZM in mice with tongue cancer $(n=18)$. (E) Gnaw-time is not correlated with time spent in the inner zone of the OF in mice with tongue cancer $(n=18)$. (F) Gnaw-time is not correlated with time spent in the open arms of the EZM in mice with tongue cancer $(n=18)$. Linear regression.

\section{DISCUSSION}

We demonstrated oral cancer induced nociception at the primary site and heterosegmental body regions (allodynia in the paw and hyperalgesia in the tail). Neither acute nor chronic cancer pain increased anxiety-like behavior in mice. Opioid agonists produced significant analgesia to widespread nociception, but did not affect anxiety-like behavior in oral cancer mice.

Pain is a clinically significant symptom in patients with oral cancer. These patients generally report pain as the most severe symptom and pain significantly impairs oral function (Hammerlid et al., 2001; Epstein et al., 2007; Viet and Schmidt, 2012). Studies have begun to reveal the peripheral mechanisms of oral cancer pain ( $Y e$ et al., 2011; Viet and Schmidt, 2012); however, it is unknown whether oral cancer causes changes in the central pathways leading to generalized pain. In the present study we demonstrated that mice with tongue cancer exhibited compromised oral function (gnawing), facial allodynia, paw allodynia, as well as tail hyperalgesia to mechanical stimulation. The behavioral changes that we observed in oral cancer mice accord with clinical data. Most patients referred for cancerrelated symptom management exhibit at least two anatomically distinct pain sites and more than $40 \%$ experience pain at four or more sites (Twycross and Fairfield, 1982). Patients with noncancer pain in the orofacial region frequently report widespread pain (Sipila et al., 2006; Chen et al., 2012; Slade et al., 2013). Taken together, our results confirm the presence of widespread nociceptive behavior in our mouse models. Several possible mechanisms could be responsible for the observed behavioral changes including psychological comorbidities such as anxiety (Gameiro et al., 2006; Imbe et al., 2006; Crettaz et al., 2013); endogenous inhibitory and/or facilitatory nociceptive pathways (Basbaum and Fields, 1984; Ossipov et al., 2010); and/or elevated levels of circulating pro-inflammatory cytokines (Sommer et al., 2008; Slade et al., 2011).

We next examined the relationship between nociception and anxiety in the setting of cancer. Despite a well-known reciprocal effect between pain and anxiety in non-cancer studies, the interaction between pain and anxiety in the context of cancer remains elusive. The prevalence of anxiety in cancer patients varies from 1 to $49 \%$ (Linden et al., 2012); most studies utilize small sample size. In three relatively large cohorts of patients with head and neck cancer $(n>300)$, the prevalence of anxiety was similar or only slightly higher than that in the general population (Hammerlid et al., 1999; BrintzenhofeSzoc et al., 2009; Brown et al., 2010; Mitchell et al., 2011; Linden et al., 2012), despite the high prevalence of pain in this population. Meta-analyses of symptom cluster studies failed to demonstrate a symptom cluster of pain and anxiety (Fan et al., 2007; Aktas et al., 2010). While pain, fatigue, and insomnia have a higher tendency to cluster, anxiety and depression tend to form a separate cluster (Aktas et al., 2010). Nevertheless, oral cancer is associated with relatively high rates of pain and anxiety compared to other cancer types and co-existence of pain and anxiety presage poor outcome in cancer patients (Haman, 2008; Brintzenhofe-Szoc et al., 2009; Brown et al., 2010; Fischer et al., 2010). Widespread pain resulting from chronic local pain is postulated as a predictor for psychological stress including anxiety (Kadam et al., 
A
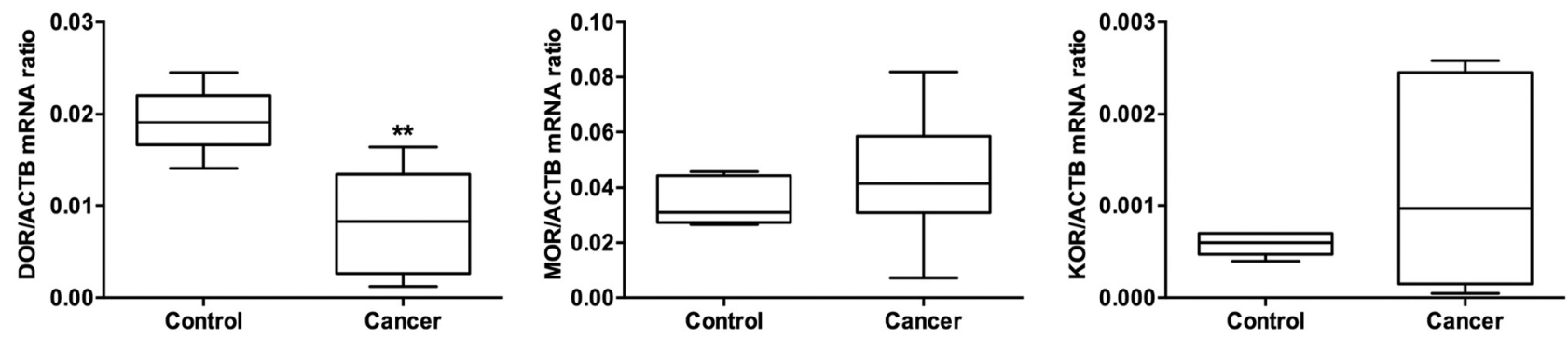

B
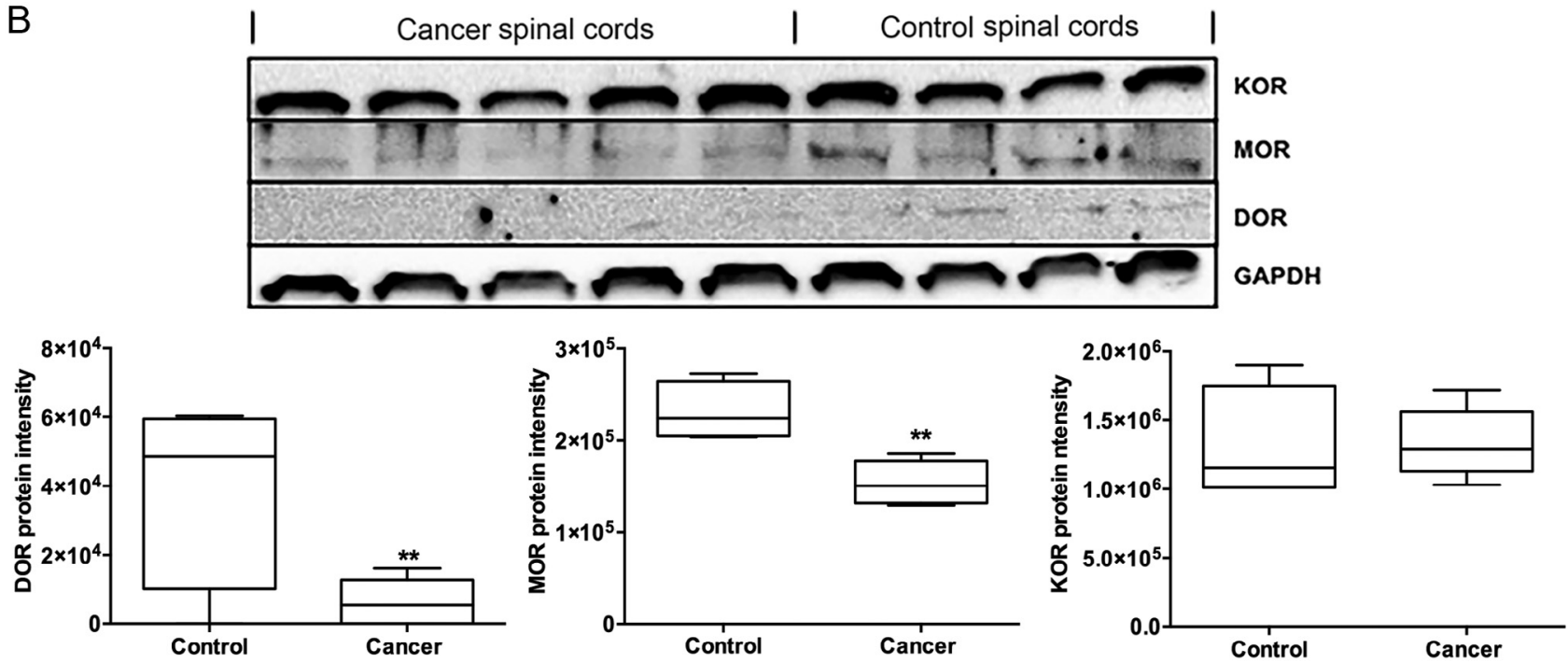

C
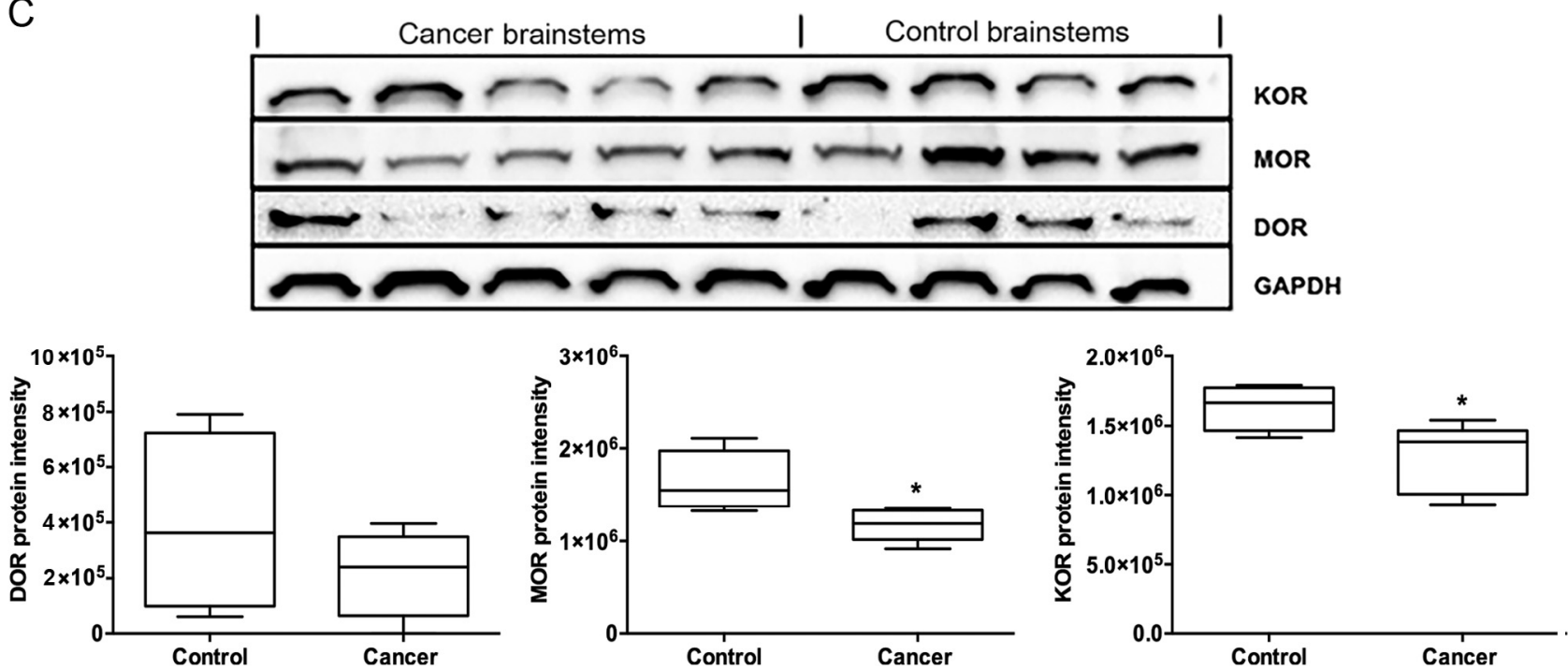

Fig. 6. Cancer mice exhibited decreased opioid receptor expression in the spinal cord and brainstem. (A) DOR mRNA expression in the spinal cord of mice with tongue cancer $(n=6)$ was significantly decreased compared to sham mice $(n=6)$. MOR or KOR mRNA expression in the spinal cord of mice with tongue cancer was not different from sham mice. (B) DOR and MOR protein expression in the spinal cord of mice with tongue cancer $(n=5)$ were significantly decreased compared to sham mice $(n=4)$. (C) MOR and DOR protein expression in the brainstem of mice with tongue cancer $(n=5)$ were significantly decreased compared to sham mice $(n=4)$. No difference was detected for DOR in the brainstem of mice with tongue cancer $(n=5)$ compared to sham mice $(n=4)$. Mann-Whitney U-test. ${ }^{*} p<0.05 ;{ }^{* *} p<0.01$.

2005; Curatolo et al., 2006). In our model, mice with tongue cancer did not exhibit increased anxiety-like behavior as measured by open field, elevated maze, defecation, or c-Fos expression in anxiety-associated brain regions despite significant nociception, tumor growth, and weight loss. Our results (along with several symptom cluster studies) suggest that cancer pain is independent of anxiety and that central sensitization (manifest as widespread pain) does not necessarily cause anxiety.

We expected that variations in nociceptive behavior might contribute to variations in anxiety-like behaviors; however we found that none of the nociceptive 

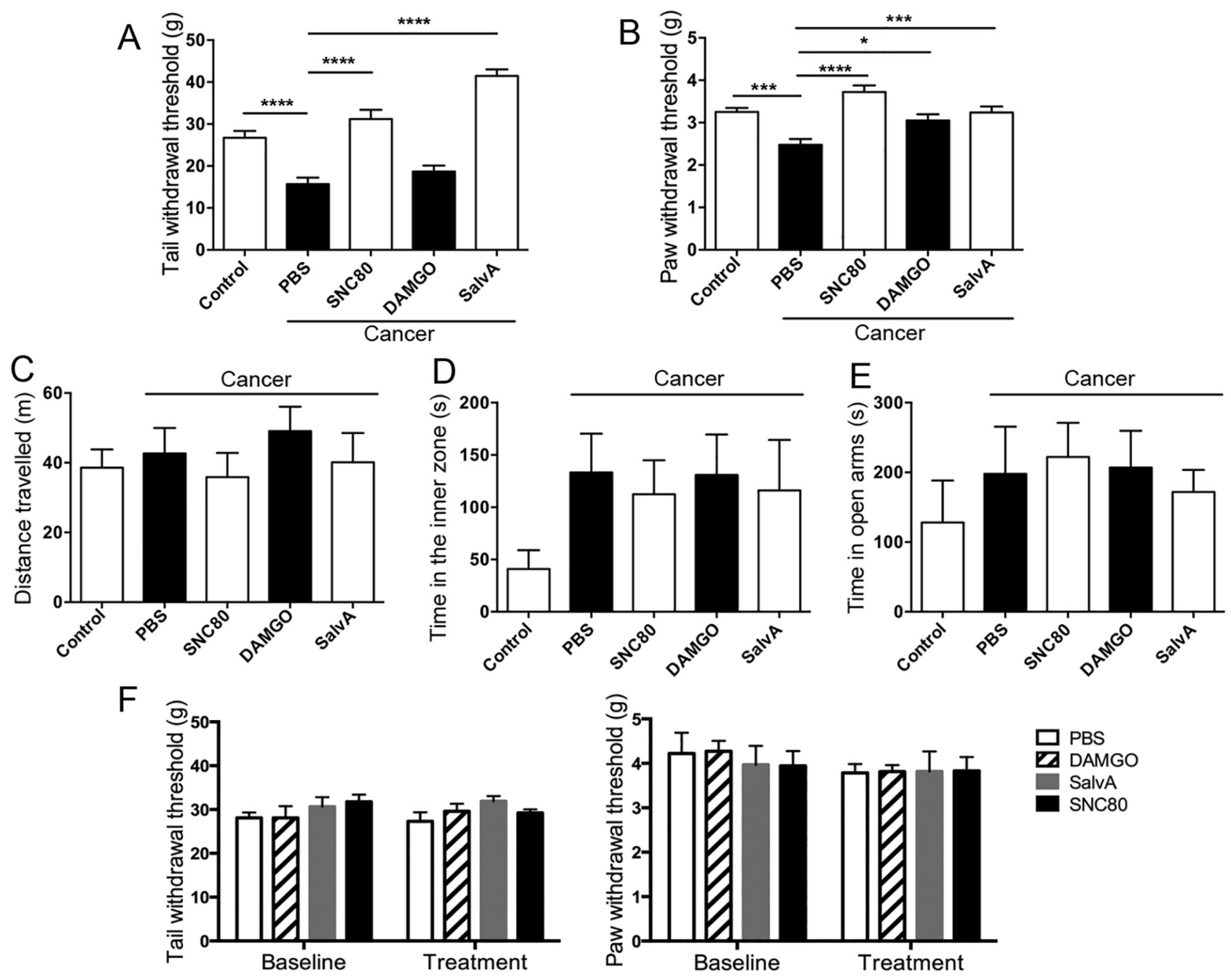

Fig. 7. Opioid agonists administered into the spinal cord inhibited widespread nociception but did not change anxiety-like behaviors. (A) SNC80 $(n=8)$ and Salvinorin $\mathrm{A}(n=8)$ significantly increased tail withdrawal threshold of mice with tongue cancer compared to vehicle-treated cancer mice $(n=8)$, while DAMGO $(n=8)$ had no effect. One-way ANOVA: $F(4,35)=3.58$; posthoc Tukey's tests: $q=4.49, p<10^{-4}$, PBS vs. control; $q=6.62, p<10^{-4}$, PBS vs. SNC80; $q=10.41, p<10^{-4}$, PBS vs. Salvinorin A. (B) SNC80, DAMGO, and Salvinorin A increased paw withdrawal thresholds of mice with tongue cancer compared to vehicle-treated mice with tongue cancer. One-way ANOVA: $F(4,35)=10.37, p<0.0001$; posthoc Tukey's tests: $q=3.85, p<0.01$, control vs. PBS; $q=6.30, p<10^{-4}$, PBS vs. SNC80; $q=2.91, p<0.05$, PBS vs. DAMGO; $q=4.04$, $p<0.001$, PBS vs. Salvinorin A. (C) Sham $(n=8)$, and cancer mice treated with vehicle $(n=8)$, SNC80 $(n=8)$, DAMGO $(n=8)$, and Salvinorin A $(n=8)$ undertook comparable travel as measured in the OF assay. One-Way ANOVA: $F(4,35)=0.46, p=0.76$. (D) No significant difference was found in time spent in the inner zone of the OF among sham mice with no cancer, or mice with tongue cancer exposed to different treatments. One-way ANOVA: $F(4,35)=1.15, p=0.35$. (E) No significant difference was found in time spent in the open arms of the EZM among sham mice with no cancer, or mice with tongue cancer with different treatments. One-way ANOVA: $F(4,35)=0.46, p=0.76$. (F) No significant difference was found for either tail withdrawal thresholds in naïve mice before and after intrathecal injection of vehicle $(n=5)$, SNC $80(n=5)$, DAMGO $(n=5)$, or Salvinorin A $(n=5)$. Interaction: $F(3,32)=0.59, p=0.63$; time factor: $F(1,32)=0.01, p=0.92$; group factor: $F(3,32)=1.49, p=0.24$. No significant difference was found for either paw withdrawal thresholds in naïve mice before and after intrathecal injection of vehicle $(n=5)$, SNC80 $(n=5)$, DAMGO $(n=5)$, or Salvinorin A $(n=5)$. Interaction: $F(3,32)=0.16, p=0.92$; time factor: $F(1,32)=1.52, p=0.23$; group factor: $F(3$, 32) $=0.12, p=0.95$. Two-way ANOVA. ${ }^{*} p<0.05 ;{ }^{* *} p<0.01,{ }^{* \star *} p<0.001,{ }^{* \star *} p<10^{-4}$.

behavioral indices were associated with anxiety-like behaviors. In a recent study examining heat hyperalgesia and anxiety-like behaviors in male rats with facial cancer, the authors found that cancer rats exhibited both heat hypersensitivity and increased anxiety-like behavior, but relief from heat hyperalgesia did not affect anxiety-like behaviors and vice versa (Gambeta et al., 2016). Their findings suggest that pain and anxiety develop with distinct mechanisms and anxiety-like behaviors might be species, strain or sex specific. For example, BALB/c mice show higher levels of anxiety-like behaviors compared to C57BL/6J mice (An et al., 2011). Female animals exhibit higher anxiety levels compared to males (Belviranli et al., 2012; Simpson and Kelly, 2012). Our female BALB/c mice might be close to their physiological plateau for anxiety prior to induction of cancer. If a floor effect is present in the animal's baseline anxiety level, the OF or EZM assays might not be sensitive enough to detect differences in anxiety between the cancer and sham control mice. A larger sample size might be required to detect these differences. Nevertheless, our findings are consistent with previous studies of mice with inflammatory pain (Urban et al., 2011) and nerve injury pain (Hasnie et al., 2007; Urban et al., 
2011): i.e., no significant differences were observed in anxiety-like behaviors measured in the OF or EZM between the pain versus pain-free groups.

Previously we demonstrated that specific opioid receptor subtypes differ in their effect on cancer pain at the primary site (Ye et al., 2012). In the current study we sought to determine whether opioid agonists could modify widespread nociception induced by cancer. MOR, DOR, and KOR are expressed extensively in the central nervous system as well as in the periphery (Fields, 2004; Ossipov et al., 2010). The opioid receptor subtypes are part of the local inhibitory neurotransmitter systems that modulate excitability of the primary sensory neurons (Inturrisi, 2002). Opioid receptors are also involved in inhibitory signaling in the dorsal horn of the spinal cord and in "top-down" descending modulation (Basbaum and Fields, 1984). Attenuation of inhibitory nociceptive control induced by cancer could lead to greater local nociception and widespread nociception. Our results in a mouse tongue cancer model demonstrate that opioid receptors in the spinal cord are responsible for changes in nociceptive behaviors measured in the paw and the tail. We found that agonists targeting the three types of opioid receptor subtypes reduce cancerinduced widespread nociception. The absence of an anti-nociceptive effect (quantified through tail withdrawal behavior) from DAMGO in cancer mice is probably due to regional differences in MOR expression or function. In addition, DOR mRNA is down regulated and protein levels of both DOR and MOR are significantly reduced in the spinal cords of cancer mice. Other than changes in expression levels, cancer might induce changes in opioid receptor phosphorylation, sensitization, and turnover (Ossipov et al., 2000, 2010; Williams et al., 2013). Our group previously reported that the MOR gene is methylated and down regulated in cancer and associated neuronal tissues (Viet et al., 2014).

In addition to its role in the generation of pain and analgesia, the opioid system also plays a role in neural modulation of anxiety. Opioid receptors and their endogenous ligands are expressed in brain structures associated with anxiety (Colasanti et al., 2011). Endogenous opioids are synthesized and released in response to stress and anxiety (Colasanti et al., 2011). In preclinical models, opioid agonists produce anxiolysis while opioid antagonists produce anxiety. Similarly, clinical studies demonstrate that activation of the opioid system leads to anxiolysis in healthy subjects and in patients with anxiety disorders (Colasanti et al., 2011). In our study, MOR, DOR, and KOR agonists (at a dose that reversed widespread nociception) did not significantly change anxietylike behavior in mice with cancer; however we observed a trend that might indicate an anxiolytic effect from these agonists. Depending on the dosage, opioid receptor agonists can produce anxiety, anxiolysis, or have no effect (Colasanti et al., 2011); accordingly, it is possible that higher doses are needed to exert an anxiolytic effect in our model.

Our findings demonstrate that cancer mice develop widespread nociception in addition to nociception at the tumor site. Reduced opioid tone in the CNS might explain widespread nociception in our oral cancer mouse model. We found that cancer-induced nociception does not contribute to anxiety-like behaviors. Future studies are needed to evaluate whether these findings are isolated to the sex, animal strain, or the type of cancer model employed.

\section{CONFLICTS OF INTEREST STATEMENT}

The authors have no conflicts of interest to declare.

Acknowledgment-The authors would like to thank Kamalpreet Singh for assisting in behavior measurements. This work is funded by NIH/NIDCR R21 DE018561 and R01 DE019796.

\section{REFERENCES}

Aktas A, Walsh D, Rybicki L (2010) Symptom clusters: myth or reality? Palliat Med 24:373-385.

An XL, Zou JX, Wu RY, Yang Y, Tai FD, Zeng SY, Jia R, Zhang X, Liu $E Q$, Broders $H$ (2011) Strain and sex differences in anxiety-like and social behaviors in C57BL/6 J and BALB/CJ mice. Exp Anim 60:111-123.

Basbaum Al, Fields HL (1984) Endogenous pain control systems: brainstem spinal pathways and endorphin circuitry. Annu Rev Neurosci 7:309-338.

Belviranli M, Atalik KE, Okudan N, Gokbel H (2012) Age and sex affect spatial and emotional behaviors in rats: the role of repeated elevated plus maze test. Neuroscience 227:1-9.

Brintzenhofe-Szoc KM, Levin TT, Li Y, Kissane DW, Zabora JR (2009) Mixed anxiety/depression symptoms in a large cancer cohort: prevalence by cancer type. Psychosomatics 50:383-391.

Brown LF, Kroenke K, Theobald DE, Wu J, Tu W (2010) The association of depression and anxiety with health-related quality of life in cancer patients with depression and/or pain. Psychooncology 19:734-741.

Chen ML, Chang HK, Yeh CH (2000) Anxiety and depression in Taiwanese cancer patients with and without pain. J Adv Nurs 32:944-951.

Chen H, Slade G, Lim PF, Miller V, Maixner W, Diatchenko L (2012) Relationship between temporomandibular disorders, widespread palpation tenderness, and multiple pain conditions: a case-control study. J Pain 13:1016-1027.

Colasanti A, Rabiner EA, Lingford-Hughes A, Nutt DJ (2011) Opioids and anxiety. J Psychopharmacol 25:1415-1433.

Crettaz B, Marziniak M, Willeke P, Young P, Hellhammer D, Stumpf A, Burgmer M (2013) Stress-induced allodynia-evidence of increased pain sensitivity in healthy humans and patients with chronic pain after experimentally induced psychosocial stress. PLoS ONE 8:e69460.

Curatolo M, Arendt-Nielsen L, Petersen-Felix S (2006) Central hypersensitivity in chronic pain: mechanisms and clinical implications. Phys Med Rehabil Clin N Am 17:287-302.

Delgado-Guay M, Parsons HA, Li Z, Palmer JL, Bruera E (2009) Symptom distress in advanced cancer patients with anxiety and depression in the palliative care setting. Support Care Cancer 17:573-579.

Dolan JC, Lam DK, Achdjian SH, Schmidt BL (2010) The dolognawmeter: a novel instrument and assay to quantify nociception in rodent models of orofacial pain. J Neurosci Methods 187:207-215.

Epstein JB, Elad S, Eliav E, Jurevic R, Benoliel R (2007) Orofacial pain in cancer: part II-clinical perspectives and management. J Dent Res 86:506-518.

Fan G, Filipczak L, Chow E (2007) Symptom clusters in cancer patients: a review of the literature. Curr Oncol 14:173-179. 
Fields H (2004) State-dependent opioid control of pain. Nat Rev Neurosci 5:565-575.

Fischer DJ, Villines D, Kim YO, Epstein JB, Wilkie DJ (2010) Anxiety, depression, and pain: differences by primary cancer. Support Care Cancer 18:801-810.

Gambeta E, Kopruszinski CM, Dos Reis RC, Zanoveli JM, Chichorro JG (2016) Evaluation of heat hyperalgesia and anxiety likebehaviors in a rat model of orofacial cancer. Neurosci Lett 619:100-105.

Gameiro GH, Gameiro PH, Andrade Ada S, Pereira LF, Arthuri MT, Marcondes FK, Veiga MC (2006) Nociception- and anxiety-like behavior in rats submitted to different periods of restraint stress. Physiol Behav 87:643-649.

Haman KL (2008) Psychologic distress and head and neck cancer: part 1-review of the literature. J Support Oncol 6:155-163.

Hammerlid E, Ahlner-Elmqvist M, Bjordal K, Biorklund A, Evensen J, Boysen M, Jannert M, Kaasa S, Sullivan M, Westin T (1999) A prospective multicentre study in Sweden and Norway of mental distress and psychiatric morbidity in head and neck cancer patients. Br J Cancer 80:766-774.

Hammerlid E, Bjordal K, AhIner-Elmqvist M, Boysen M, Evensen JF, Biorklund A, Jannert M, Kaasa S, Sullivan M, Westin T (2001) A prospective study of quality of life in head and neck cancer patients. Part I: at diagnosis. Laryngoscope 111:669-680.

Hasnie FS, Wallace VC, Hefner K, Holmes A, Rice AS (2007) Mechanical and cold hypersensitivity in nerve-injured C57BL/6 J mice is not associated with fear-avoidance- and depressionrelated behaviour. Br J Anaesth 98:816-822.

Heim HM, Oei TP (1993) Comparison of prostate cancer patients with and without pain. Pain 53:159-162.

Imbe H, Iwai-Liao Y, Senba E (2006) Stress-induced hyperalgesia: animal models and putative mechanisms. Front Biosci 11:2179-2192.

Inturrisi CE (2002) Clinical pharmacology of opioids for pain. Clin J Pain 18:S3-13.

Kadam UT, Thomas E, Croft PR (2005) Is chronic widespread pain a predictor of all-cause morbidity? A 3 year prospective population based study in family practice. J Rheumatol 32:1341-1348.

Kalueff AV, Tuohimaa P (2004) Experimental modeling of anxiety and depression. Acta Neurobiol Exp (Wars) 64:439-448.

Linden W, Vodermaier A, Mackenzie R, Greig D (2012) Anxiety and depression after cancer diagnosis: prevalence rates by cancer type, gender, and age. J Affect Disord 141:343-351.

Luger NM, Sabino MA, Schwei MJ, Mach DB, Pomonis JD, Keyser CP, Rathbun M, Clohisy DR, Honore P, Yaksh TL, Mantyh PW (2002) Efficacy of systemic morphine suggests a fundamental difference in the mechanisms that generate bone cancer vs inflammatory pain. Pain 99:397-406.

Mitchell AJ, Chan M, Bhatti H, Halton M, Grassi L, Johansen C, Meader N (2011) Prevalence of depression, anxiety, and adjustment disorder in oncological, haematological, and palliative-care settings: a meta-analysis of 94 interview-based studies. Lancet Oncol 12:160-174.

Mogil JS (2009) Animal models of pain: progress and challenges. Nat Rev Neurosci 10:283-294.

Ono K, Ye Y, Viet CT, Dang D, Schmidt BL (2015) TRPV1 expression level in isolectin $\mathrm{B}_{4}$-positive neurons contributes to mouse strain difference in cutaneous thermal nociceptive sensitivity. J Neurophysiol 113:3345-3355.

Ossipov MH, Lai J, Malan Jr TP, Porreca F (2000) Spinal and supraspinal mechanisms of neuropathic pain. Ann N Y Acad Sci 909:12-24.

Ossipov MH, Dussor GO, Porreca F (2010) Central modulation of pain. J Clin Invest 120:3779-3787.

Paxinos G, Franklin K (2012) Paxinos and Franklin's the mouse brain in stereotaxic coordinates. 4th ed. Cambridge, Massachusetts: Academic Press.
Rabbitts JA, Holley AL, Groenewald CB, Palermo TM (2016) Association between widespread pain scores and functional impairment and health-related quality of life in clinical samples of children. J Pain 17:678-684.

Romero-Reyes M, Ye Y (2013) Pearls and pitfalls in experimental in vivo models of headache: conscious behavioral research. Cephalalgia 33:566-576.

Sareen J, Cox BJ, Clara I, Asmundson GJ (2005) The relationship between anxiety disorders and physical disorders in the U.S. National Comorbidity Survey. Depress Anxiety 21:193-202.

Schmidt BL, Hamamoto DT, Simone DA, Wilcox GL (2010) Mechanism of cancer pain. Mol Interv 10:164-178.

Simpson J, Kelly JP (2012) An investigation of whether there are sex differences in certain behavioural and neurochemical parameters in the rat. Behav Brain Res 229:289-300.

Sipila K, Ylostalo PV, Joukamaa M, Knuuttila ML (2006) Comorbidity between facial pain, widespread pain, and depressive symptoms in young adults. J Orofac Pain 20:24-30.

Slade GD, Conrad MS, Diatchenko L, Rashid NU, Zhong S, Smith S, Rhodes J, Medvedev A, Makarov S, Maixner W, Nackley AG (2011) Cytokine biomarkers and chronic pain: association of genes, transcription, and circulating proteins with temporomandibular disorders and widespread palpation tenderness. Pain 152:2802-2812.

Slade GD, Smith SB, Zaykin DV, Tchivileva IE, Gibson DG, Yuryev A, Mazo I, Bair E, Fillingim R, Ohrbach R, Greenspan J, Maixner W, Diatchenko L (2013) Facial pain with localized and widespread manifestations: Separate pathways of vulnerability. Pain. http:// dx.doi.org/10.1016/j.pain.2013.07.009.

Sommer C, Hauser W, Gerhold K, Joraschky P, Petzke F, Tolle T, Uceyler N, Winkelmann A, Thieme K (2008) Etiology and pathophysiology of fibromyalgia syndrome and chronic widespread pain. Schmerz 22:267-282.

Teh CF, Morone NE, Karp JF, Belnap BH, Zhu F, Weiner DK, Rollman BL (2009) Pain interference impacts response to treatment for anxiety disorders. Depress Anxiety 26:222-228.

Twycross RG, Fairfield S (1982) Pain in far-advanced cancer. Pain 14:303-310.

Urban R, Scherrer G, Goulding EH, Tecott LH, Basbaum Al (2011) Behavioral indices of ongoing pain are largely unchanged in male mice with tissue or nerve injury-induced mechanical hypersensitivity. Pain 152:990-1000.

van den Beuken-van Everdingen MH, de Rijke JM, Kessels AG, Schouten HC, van Kleef M, Patijn J (2007) Prevalence of pain in patients with cancer: a systematic review of the past 40 years. Ann Oncol 18:1437-1449.

Viet CT, Schmidt BL (2012) Biologic mechanisms of oral cancer pain and implications for clinical therapy. J Dent Res 91:447-453.

Viet CT, Dang D, Ye Y, Ono K, Campbell RR, Schmidt BL (2014) Demethylating drugs as novel analgesics for cancer pain. Clin Cancer Res 20:4882-4893.

Williams JT, Ingram SL, Henderson G, Chavkin C, von Zastrow M, Schulz S, Koch T, Evans CJ, Christie MJ (2013) Regulation of mu-opioid receptors: desensitization, phosphorylation, internalization, and tolerance. Pharmacol Rev 65:223-254.

Woolf CJ (2011) Central sensitization: Implications for the diagnosis and treatment of pain. Pain 152:S2-S15.

Ye Y, Dang D, Zhang J, Viet CT, Lam DK, Dolan JC, Gibbs JL, Schmidt BL (2011) Nerve growth factor links oral cancer progression, pain, and cachexia. Mol Cancer Ther 10:1667-1676.

Ye Y, Dang D, Viet CT, Dolan JC, Schmidt BL (2012) Analgesia targeting IB4-positive neurons in cancer-induced mechanical hypersensitivity. J Pain 13:524-531.

Zhang S, Jin X, You Z, Wang S, Lim G, Yang J, McCabe M, Li N, Marota J, Chen L, Mao J (2014) Persistent nociception induces anxiety-like behavior in rodents: role of endogenous neuropeptide S. Pain 155:1504-1515. 